\title{
Hepatocellular Carcinoma with Congenital Absence of the Portal Vein in a Child
}

\author{
Nurdan Tacyildiz, Emine Gulsah Ozdemir, Zulfikar Gordu, Emel Unal, Gulsan Yavuz, Handan Ugur Dincaslan*, Omer Suat Fitoz, Meltem \\ Kologlu, Deniz Balci and Gulnur Gollu Bahadir \\ Ankara University School of Medicine, Turkey
}

\begin{abstract}
Congenital absence of the portal vein (CAPV) is such a rare malformation of the splanchnic venous system. Also it can be a reason for hepatic tumors, for example adenoma, hepatoblastoma or hepatocellular carcinoma (HCC). The cooccurence of CAPV and HCC in adult patients have been reported in the literature. It is the second case of a pediatric patient whom has also CAPV and HCC.
\end{abstract}

\section{Introduction}

Congenital absence of the portal vein (CAPV) and its intra-hepatic branches is a malformation of the splanchnic venous system described by John Abernethy in 1973 [1]. Almost thirty cases have been reported to date $[2,3]$. CAPV is generally seen in children and associated with multiple anomalies for example skeletal abnormities, cardiac failure and hepatic tumours [4]. The co-occurence of CAPV and hepatocellular carcinoma (HCC) has been described in three adults and in only one child $[5,6]$. We present a pediatric patient with concomitant occurrance of HCC and CAPV.

\section{Case Report}

A 5 years old girl was admitted to pediatrics department of another hospital generel with pollakiuria and loss of appetite since 2 years. Abdominal ultrasounography showed an iso/hyperechoic liver mass about $35 \mathrm{~mm}$ involving segment 7 which has a hypoechoic halo and peripheric vascularisation. Then the patient was referred to pediatric oncology department of our hospital for further investigation. She has a history of term birth with normal birth weight and she has no significant medical history. There was no history of malignancy in her family.

Her weight and height values were in normal percentiles. The pathological findings were bilateral submandibuler lymphadenopathies about $1.5 \mathrm{~cm}$ and $2 / 6$ systolic murmur at mesocardiac region. Liver and spleen were not palpable. Liver function tests were as follows; AST $45 \mathrm{U} / \mathrm{L}(\mathrm{N}<35)$, ALT $29 \mathrm{U} / \mathrm{l}(\mathrm{N}<40)$, Alkaline phosphatase 201 $\mathrm{U} / \mathrm{L}(\mathrm{N}<110), \mathrm{LDH}: 2198 \mathrm{U} / \mathrm{L}(\mathrm{N}<220)$ and total bilirubin: $0.76 \mathrm{mg} /$ $\mathrm{dl}(<1.10)$. The ammonia level was normal. Initial a-fetoprotein was $2.86 \mathrm{ng} / \mathrm{ml}(\mathrm{N}: 0-9)$. A search for tumor markers CA125: 55.1 U/ml (035) and HBsAg, anti-HBs antibodies and Anti-HCV antibodies were negative. She had been investigated for metabolic disorders which can cause HCC, for example hereditary tyrosinemia and alpha-1 antitrypsin deficiency, serum tyrosin level: $142.44 \mu \mathrm{mol} / \mathrm{L}(32-275)$ and $\alpha-1$ AT: 1. $14 \mathrm{~g} / \mathrm{L}(\mathrm{N})$, so we had ruled out metabolic disorders.

Computed tomography revealed two solid lesions, larger one localized in the segment 8 of the liver. The lesion was extending from the dome of the liver to the portal hilum. Right hepatic vein was compressed and displaced to posteriorly. Central hypervascular nodular enhancement was observed in the arterial phase of CT imaging. The smaller lesion was located in the segment 6 . It was isodense with the liver parenchyma in the arterial phase and hypodense on delayed venous phase images. The CT examination also revealed an absence of the main portal vein (Figure 1). Superior mesenteric vein was coursing left of the midline at the level of the head of pancreas and after joining with the splenic vein at the level of the pancreatic tail they both

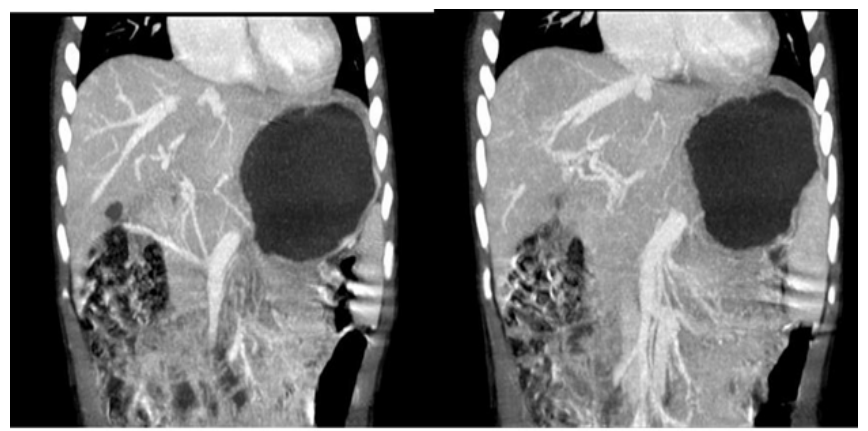

Figure 1: Abdominal contrast-enhanced computed tomography showing the absence of main portal vein.

were draining into the hemiazygos vein. No pathological uptake was observed on PET scans. Echocardiography was normal.

Ultrasound-guided fine-needle aspiration biopsy was performed from the segment 8 lesion. Reticulin network loss and sinusoidal CD34 expression were preserved within the tumor that supports the malignancies but staining pattern with $\beta$-catenin does not support malignancies. The pathology report of the biopsy material was "atypical hepatocytic nodule" and surgical excision of the mass had been suggested. Thus, the patient underwent surgery and right hepatectomy was performed. Surgeon noted that extrahepatic portal vein and its right and left branches were absent. Standart right hepatectomy was done without any difficulty.

Microscopic examination demonstrated "Multifocal hepatocellular carcinoma, grade II" noting surgical margins and the liver capsule was tumor-free and also base structure of the parenchyma was protected. According to The European staging system, considers only the pretreatment extent of disease, (PRETEXT, the PRETreatment EXTent of disease scoring system), our patient was Stage II because tumor

${ }^{*}$ Corresponding author: Handan Ugur Dincaslan, Ankara University School of Medicine, Turkey, E-mail: handanprl@hotmail.com

Received February 12, 2015; Accepted March 21, 2015; Published March 24 2015

Citation: Tacyildiz N, Ozdemir EG, Gordu Z, Unal E, Yavuz G, et al. (2015) Hepatocellular Carcinoma with Congenital Absence of the Portal Vein in a Child. J Clin Case Rep 5: 504. doi:10.4172/2165-7920.1000504

Copyright: @ 2015 Tacyildiz N, et al. This is an open-access article distributed under the terms of the Creative Commons Attribution License, which permits unrestricted use, distribution, and reproduction in any medium, provided the original author and source are credited. 
involves two adjoining quadrants (segments 6 and 8). According to the post-surgical North American staging system, our patient is stage I which means no metastases and tumor completely resected [7].

Two months after surgery, patient recieved two cycles of chemotherapy POG-8697 regimen which including Cisplatin (100 $\mathrm{mg} / \mathrm{m}^{2}$ iv infused-Day 1$)$, Vincristin $\left(1.5 \mathrm{mg} / \mathrm{m}^{2}\right.$ iv-Day $\left.3,10,17\right)$ and 5 -florourasil ( $600 \mathrm{mg} / \mathrm{m}^{2}$ iv-Day 3$)$. According to a POG study 3 years evidence free survey is $91 \%$ for stage I and II patients which treated with POG-8697 regimen [8].

Two months later, in order to evaluate the response to treatment, computed tomography was performed and no recurrent or residual lesion was detected. The patient is doing well during 8 months follow-up.

\section{Discussion}

Malignant liver tumors are seen rarely that's about $<1 \%$ of all pediatric malignancies [7]. Contrary to adults, in whom the predominant malignency is hepatocellular carcinoma, hepatoblastoma accounts for $70 \%$ in children. Hepatocellular carcinoma is the most frequent hepatic malignancy in adolescents. Generally, hepatic viral infection like HBV, $\mathrm{HCV}$ or cirrhosis is related with hepatocellular carcinoma and it can take decades for malignancy to develop, because of this it is seen in very young children rarely. CAPV is another reason for HCC in adults. There are only a few pediatric cases who has HCC associated with CAPV in the literature $[5,6]$.

CAPV is an uncommon anomaly in which the splanchnic venous flow is diverted away from the liver and drains into the systemic circulation. It is fewly symptomatic and other congenital abnormalities which are cardiovascular like dextrocardia, ventricular oratrial septal defects, patent foramen ovale and ductus arteriosus; skeletal such as hemivertebrae, fifth finger anomalies, oculoauriculovertebral dysplasia; gastrointestinale for example biliary atresia, liver tumors and urinary like cystic renal dysplasia, hipospadias, vesico-uretheral reflux can be associated [9-12]. Liver tumors have been described in the presence of distracted portal venous flow and they can be benign (focal nodular hyperplasia, adenoma) or malignant lesions (hepatoblastoma, HCC) $[13,14]$.

If we consider how CAPV cause liver tumor; hepatotrophic factors such as pancreatic hormones carried by portal system may be the answer. They may initiate regeneration of hepatic cells [15]. With the absence of portal hepatic perfusion results in change of hepatic cell structure [16]. Absence of portal venous flow may be compensated by a stronger arterial flow then it leads to the development of intrahepatic nodular lesions[17].

In our case, we could not find any infectious, metabolic, or genetical reason that causes HCC except CAPV. Interestingly, our patient is 5 years old and there is not long time to develop HCC. That made us think CAPV may be affected the case since fetal life and/or type of CAPV also may be important for developing HCC.

\section{Conclusion}

Since our patient is one of the rare cases which reported in the literature, a relationship between portal vein agenesis and HCC needs to be explained with more cases with multicenter studies. In children, HCC is usually associated with metabolic diseases, usually after progression of the disease to cirrhosis. There also is an increased prevalence of HCC in children in areas where there is high hepatitis B virus exposure [18]. Our patient did not have an underlying cirrhotic liver and was negative for hepatitis B virus and she received hepatitis-B vaccine in infancy. Here, we would like to stress the importance of hepatitits B vaccinization for help protect yourself from hepatitis B infection especially in developing countries.

On the other hand follow-up protocols and preventive procedures should be established for these children. Early diagnosis of recurrent disease of our patient is important since vascular anomaly of portal vein may be still affecting. Cadaveric liver transplantation can be done if the patient has recurrent disease during follow-up.

\section{References}

1. Abernethy J, Banks J (1793) Account of two instances of uncommon formation in the viscera of the human body. Philos Trans R Soc 83: 59-66.

2. Kohda E, Saeki M, Nakano M, Masaki H, Ogawa K, et al. (1999) Congenital absence of the portal vein in a boy. Pediatr Radiol 29: 235-237.

3. Altavilla G, Guariso G (1999) Focal nodular hyperplasia of the liver associated with portal vein agenesis: a morphological and immunohistochemical study of one case and review of the literature. Adv Clin Pathol 3: 139-145.

4. Mistinova J, Valacsai F, Varga I (2010) Congenital absence of the portal vein case report and a review of literature. Clin Anat 23: 750-758.

5. Morotti RA, Killackey M, Shneider BL,Repucci A, Emre S, et al. (2007) Hepatocellular carcinoma and congenital absence of the portal vein in a child receiving growth hormone therapy for turner syndrome. Semin Liver Dis 27 : 427-431.

6. Taïeb J, Castera L, Boige V, Frouge C, Bedossa P, et al. (1998) Hepatocellular carcinoma complicating agenesis of the portal vein. Gastroenterol Clin Biol 22 : 246-247.

7. Litten JB, Tomlinson GE (2008) Liver tumors in children. Oncologist 13: 812

8. Douglass EC, Reynolds M, Finegold M, Cantor AB, Glicksman A (1993) Cisplatin, vincristine, and fluorouracil therapy for hepatoblastoma: A Pediatric Oncology Group study. J Clin Oncol 11: 96-99

9. Massin M, Verloes A, Jamblin P (1999) Cardiac anomalies associated with congenital absence of the portal vein. Cardiol Young 9: 522-525.

10. Taoube KA, Alonso Calderon JL, Yandza T, St Vil D, Blanchard H (1999) Congenital absence of portal vein in a girl with biliary atresia treated with liver transplant. Cir Pediatr 12: 38-40.

11. Guariso G, Fiorio S, Altavilla G, Gamba PG, Toffolutti T, et al. (1998) Congenital absence of the portal vein associated with nodular hyperplasia of the liver and cystic dysplasia of the kidney. Eur J Pediatr157: 287-290.

12. Matsuoka Y, Ohtomo K, Okubo T, Nishikawa J, Mine T,et al. (1992) Congenital absence of the portal vein. Gastrointest Radiol 17: 31-33.

13. Barton JW, Keller MS (1989) Liver transplantation for hepatoblastoma in child with congenital absence of the portal vein. Pediatr Radiol 20: 113-114.

14. Kawakatsu M, Vilgrain V, Belghiti J, Flejou JF, Nahum H (1994) Association of multiple liver adenomas with spontaneous intrahepatic portohepatic shunt. Abdom Imaging 19: 438-440.

15. Starzl TE, Francavilla A, Halgrimson CG, Francavilla FR, Porter KA, et al (1973) The origin, hormonal nature, and action of hepatotrophic substances in portal venous blood. Surg Gynecol Obstet 137: 179-199.

16. Kondo $F$ (2001) Benign nodular hepatocellular lesions caused byabnorma hepatic circulation: etiological analysis and introduction of a new concept. J Gastroenterol Hepatol 16: 1319-1328.

17. Scheuermann U, Foltys D, Otto G (2012) Focal nodular hyperplasia precedes hepatocellular carcinoma in an adult with congenital absence of the portal vein Transpl Int 25: 67-68.

18. Moore SW, Millar AJ, Hadley GP, lonescu G, Kruger M, et al. (2004) Hepatocellular carcinoma and liver tumors in South African children: a case for increased prevalence. Cancer 101: 642-649. 